\title{
DIETARY INADEQUACIES IN THE ELDERLY WITH ALZHEIMER'S DISEASE FOLLOWED AT THE REFERENCE HEALTH CENTER FOR ELDERLY CARE IN CURITIBA - BRAZIL
}

\author{
D. Rodrigues Lecheta1, M.E. Madalozzo Schieferdecker' ${ }^{1}$ A.P. de Mello², I. Berkenbrock \\ J. Cardoso Neto ${ }^{1}$, E.M.C. Pereira Maluf ${ }^{1}$
}

\begin{abstract}
Background: Dietary changes are frequent in Alzheimer's disease (AD). Objective: to assess the dietary intake of elderly with AD. Design: cross sectional study. Setting: AD patients followed at the Health Center of Elderly Care Ouvidor Pardinho, in Curitiba/Brazil, from November/2010 to July/2011. Participants: 96 individuals. Measurements: the scales used were the Mini Nutritional Assessment to determine the nutritional status and the Clinical Dementia Rating to set the stage of dementia. The average food intake of three days was analyzed for energy, carbohydrates, protein, fat, vitamin A, vitamin C, calcium, iron and liquids, and compared with the individualized nutritional recommendations. Results: 96 elderly patients were evaluated. The mean age was $78.0 \pm 6.52$ years, and most of them had mild AD (54.2\%) and risk of malnutrition (55.2\%). All of them were oral fed and $37.5 \%$ received modified consistency food. Regarding independence for feeding: $44.8 \%$ of the elderly needed assistance to serve food, $31.3 \%$ did not eat when the meal was not offered by the caregiver, and $31.3 \%$ ate less than usual. Regarding dietary adequacy: $41.7 \%$ had low-calorie diet, $46.9 \%$ low-protein diet, and most of the patients had insufficient intake of vitamins A and C, calcium and iron. Decreased appetite occurred in $31.3 \%$ of the elderly. Conclusion: the dietary intake of AD patients is inadequate when compared with nutritional recommendations. Caregivers should be informed about the need of specialized nutritional monitoring and feeding assistance for the demented patient since the early stage of the disease.
\end{abstract}

Key words: Alzheimer disease, diet, nutritional status.

\section{Introduction}

Alzheimer's disease (AD) is the most common type of dementia, accounting for 60 to $70 \%$ of the cases (1). The loss of memory is one of the earliest and most pronounced symptoms. As the disease advances, trouble with language, intellectual performance, independence and autonomy are frequent (2). It is also usual dietary changes, as decreased appetite, difficulty with chewing, dysphagia, food refusal $(2,3,4)$ and body composition alterations, such as unintentional weight loss (3), accelerated loss of muscle mass and sarcopenia $(5,6)$. Studies have described the high prevalence of malnutrition in elderly patients with $\operatorname{AD}(7,8)$ and their poorer nutritional and functional status compared to the ones without dementia (9).

\footnotetext{
1. Federal University of Paraná, Brazil; 2. Clinical Hospital of Federal University of Paraná, Brazil; 3. Curitiba Municipal Secretary of Health, Brazil

Corresponding Author: Danielle Rodrigues Lecheta, Federal University of Paraná, Brazil, 54, Osman Ahamad Gebara street, Parque Alvorada, Zip code 79823-461, Dourados / MS, Brazil, Telephone numbers: (005567) 3032-6360 / (005567) 8171-3288, danilecheta@gmail.com
}

The etiology of weight loss and malnutrition in AD seems to be multifactorial. Several hypotheses have been proposed to explain it, but none has been proven (3). It is presently unclear whether the energy imbalance and the accompanying weight loss associated with $\mathrm{AD}$ are caused by reduced energy intake, elevated energy expenditure, or a combination of both (5). Also, it is possible that the causes vary depending on the stage of dementia. Early in the disease, when the patient is still able to self-feed, malnutrition may be related to behavioral disorders, associated depression or other comorbidities (10), while in advanced stages, behavioral disturbances, cognitive deficit, impossibility of eating without help and dysphagia assume a central role (11). According to Roque, Salva and Vellas (10), demented patients who are dependent for eating have a relative risk of 8.25 for malnutrition.

Some researchers have examined the adequacy of diets offered to these patients and found that the diets were adequate (12) or suboptimal $(7,8)$. However, other studies showed that the weight loss was not accompanied by decreased energy intake $(3,13)$. 
The aim of this study is to assess the dietary intake of $\mathrm{AD}$ patients followed at the Health Center of Elderly Care.

\section{Methods}

This is a cross sectional study. The research project was approved by the Ethics Committee of Curitiba Municipal Secretary of Health, with protocol number 132/2010. The study included elderly patients with the diagnosis of probable AD, followed at the Health Center of Elderly Care Ouvidor Pardinho, which is the reference to assist the elderly with AD in the city of Curitiba (southern Brazil), users of the public health system. The diagnosis of probable $\mathrm{AD}$ was made according to the criteria of the National Institute of Neurological and Communicative Disorders and Strokes - Task Force on Alzheimer's Disease (14). The minimum sample size was estimated at 90 individuals, considering confidence interval of $95 \%$ and margin of error of less than $10 \%$.

The inclusion criteria were: to be 60 years old or more, to have the diagnosis of probable AD and to be accompanied by the primary caregiver for data collection. The exclusion criteria were: to reside in long-term care institutions, to have chronic renal or heart failure or consumptive diseases, to be unable to stand up to assess the current weight and primary caregiver unable to write the food record.

The patients screening was done by a geriatrician doctor from November 2010 to July 2011. Written instructions and the forms for food record were given to the caregiver and the date for the data collection was scheduled.

After the caregiver and/or the patient signed the Informed Consent Form, the patient was assessed by a trained nutritionist. Information about feeding, and also demographic, economic and cultural data was collected in the interview. The stage of AD was classified in mild, moderate and severe according to the Clinical Dementia Rating (CDR) $(15,16)$. The Mini Nutritional Assessment (MNA) (17) was performed to determine the nutritional status of the elderly; scores greater than 23.5 indicate normal weight, 17 to 23.5 nutritional risk and under 17 malnutrition. In the items of MNA regarding perceived health and nutritional status, it was considered the responses provided by the caregiver.

The anthropometric assessment was performed according to standard techniques; weight, height, arm circumference $(A C)$, calf circumference $(C C)$, triceps skinfold (TSF) and subscapular skinfold were collected. Circumferences and skinfolds were obtained on the right side, assessed three times and then the average value was figured. Arm muscle circumference (AMC) was calculated $(\mathrm{AMC}=\mathrm{AC}(\mathrm{cm})-\pi \times[\mathrm{TSF}(\mathrm{mm}) / 10])$. Body Mass Index (BMI) was calculated $\left(B M I\left(\mathrm{~kg} / \mathrm{m}^{2}\right)=\right.$ weight / height ${ }^{2}$ ) and the result was interpreted as the reference values for elderly population: underweight, less than 22 $\mathrm{kg} / \mathrm{m} 2$; normal weight, from 22 to 26.9; and overweight, 27 or more.

The following biochemical tests were performed: hemoglobin, total lymphocytes, albumin and total cholesterol. The reference values for adequate nutritional status were: hemoglobin $\geq 12.0 \mathrm{~g} / \mathrm{dl}$ in females and $\geq 14.0$ $\mathrm{g} / \mathrm{dL}$ for males; total lymphocytes $\geq 2000 / \mathrm{mm}^{3}$; albumin $\geq 3.5 \mathrm{~g} / \mathrm{dl}$; and total cholesterol $\geq 150 \mathrm{mg} / \mathrm{dl}$ (18).

The food intake of the patients was analyzed with the three day food record, registered by the caregivers. The nutrient intake was calculated using the software Avanutri version 4.0, for energy, carbohydrate, protein, fat, vitamin A, vitamin C, calcium, iron and liquids. The values were obtained by the average intake of the three days.

The energy recommendation was according to the DRIs (Dietary Reference Intake), through the prediction equations proposed for the calculation of total energy expenditure (TEE) (19), which considers gender, age, weight, height and physical activity. For weight gain, the energy recommendation was 30 to 35 calories per kilogram of body weight (20). The protein recommendation was $1.0 \mathrm{~g}$ of protein per kilogram of body weight (20); higher values were used in the presence of wounds or hypoalbuminemia. The liquid recommendation was 25 to $30 \mathrm{ml}$ per kilogram of body weight (20) or more if diarrhea or fever.

The micronutrients recommendations were according to the DRIs. For elderly men: $900 \mu \mathrm{g} / \mathrm{d}$ of vitamin A (as retinol equivalents), $90 \mathrm{mg} / \mathrm{d}$ of vitamin C, $1200 \mathrm{mg} / \mathrm{d}$ of calcium and $8 \mathrm{mg} / \mathrm{d}$ of iron. For elderly women: 700 $\mu \mathrm{g} / \mathrm{d}$ of vitamin A (as retinol equivalents), $75 \mathrm{mg} / \mathrm{d}$ of vitamin C, $1200 \mathrm{mg} / \mathrm{d}$ of calcium and $8 \mathrm{mg} / \mathrm{d}$ of iron.

Statistical analysis was performed with SPSS Statistics 17.0, Statgraphics Centurion and software $R$ version 2.13.0. The nonparametric Kruskal-Wallis test was used to compare the values of the variables among the different stages of $\mathrm{AD}$ (mild, moderate and severe). The nonparametric chi-square test to assess differences in frequencies among groups of variables. For variables with statistically significant difference, the multiple comparisons test was used to check for pairs of groups in which differences were found. In all statistical analysis $p$ $<0.05$ was considered statistically significant.

\section{Results}

Among the 328 screened patients, 187 were eligible for the study. Of these, 96 patients and caregivers agreed to participate and were evaluated. Ninety-one respondents refused to participate; in 79 cases the caregiver refused and in 12 cases the patient did. The main reasons given were lack of time and difficulty in taking the elderly to the health center.

The population of the study is predominantly female $(\mathrm{n}=68,70.8 \%)$ with mean age of 78.0 years $( \pm 6.52)$, ranging from 60 to 94 years. Most of the individuals had 
Table 1

Characteristics of patients with Alzheimer disease

\begin{tabular}{|c|c|c|}
\hline Characteristic & $\mathrm{n}(\%) \mathrm{n}=96$ & Mean \pm DP \\
\hline Sex & $96(100)$ & \\
\hline Female & $68(70,8)$ & \\
\hline Male & $28(29,2)$ & \\
\hline Age (years) & $96(100)$ & $78.0 \pm 6.52$ \\
\hline$\geq 60$ e $\leq 69$ & $10(10,4)$ & \\
\hline$\geq 70 \mathrm{e} \leq 79$ & $43(44,8)$ & \\
\hline$\geq 80$ & $43(44,8)$ & \\
\hline Education (years) & $96(100)$ & $4.4 \pm 4.40$ \\
\hline Illiterate & $12(12,5)$ & \\
\hline Incomplete or complete primary education & $69(71,9)$ & \\
\hline Incomplete or complete middle education & $8(8,3)$ & \\
\hline Incomplete or complete higher education & $7(7,3)$ & \\
\hline Per capita income & $94(97,9)^{*}$ & \\
\hline$\leq 1$ Brazilian minimum wage & $31(32,3)$ & \\
\hline$>1 \mathrm{e} \leq 2$ Brazilian minimum wage & $34(35,4)$ & \\
\hline$>2 \mathrm{e} \leq 4$ Brazilian minimum wage & $22(22,9)$ & \\
\hline$>4$ Brazilian minimum wage & $7(7,3)$ & \\
\hline CDR & $96(100)$ & \\
\hline Mild & $52(54,2)$ & \\
\hline Moderate & $33(34,4)$ & \\
\hline Severe & $11(11,5)$ & \\
\hline MNA (points) ₹ & $96(100)$ & $22,3 \pm 3,52$ \\
\hline Malnutrition & $5(5,2)$ & \\
\hline Nutritional risk & $53(55,2)$ & \\
\hline Normal nutritional status & $38(39,6)$ & \\
\hline Weight (kg) & $96(100)$ & $58,1 \pm 10,57$ \\
\hline Height (cm) & $96(100)$ & $155,0 \pm 9,82$ \\
\hline BMI $\left(\mathrm{kg} / \mathrm{m}^{2}\right)$ & $96(100)$ & $24,1 \pm 3,53$ \\
\hline Underweight & $26(27,1)$ & \\
\hline Normal weight & $51(53,1)$ & \\
\hline Overweight & $19(19,8)$ & \\
\hline Arm circumference $(\mathrm{cm})$ & $96(100)$ & $28,9 \pm 3,07$ \\
\hline Arm muscle circumference $(\mathrm{cm})$ & $96(100)$ & $24,4 \pm 2,69$ \\
\hline Calf circumference $(\mathrm{cm})$ & $96(100)$ & $32,6 \pm 2,72$ \\
\hline Triceps skinfold (mm) & $96(100)$ & $14,4 \pm 5,49$ \\
\hline Subscapular skinfold (mm) & $96(100)$ & $17,8 \pm 8,68$ \\
\hline Hemoglobin $(\mathrm{g} / \mathrm{dl}) \S$ & $94(97,9)$ & $13,7 \pm 1,24$ \\
\hline Normal & $78(83,0)$ & \\
\hline Reduced & $16(17,0)$ & \\
\hline Total lymphocytes $\left(/ \mathrm{mm}^{3}\right) \S$ & $94(97,9)$ & $2014,5 \pm 721,26$ \\
\hline Normal & $42(44,7)$ & \\
\hline Reduced & $52(55,3)$ & \\
\hline Albumin $(\mathrm{g} / \mathrm{dl}) \S$ & $95(99,0)$ & $4,3 \pm 0,36$ \\
\hline Normal & $94(98,9)$ & \\
\hline Reduced & $1(1,1)$ & \\
\hline Total cholesterol $(\mathrm{mg} / \mathrm{dl}) \S$ & $95(99,0)$ & $197,6 \pm 42,41$ \\
\hline Normal & $84(88,4)$ & \\
\hline Reduced & $11(11,6)$ & \\
\hline
\end{tabular}


Table 2

The feeding of patients with Alzheimer disease

\begin{tabular}{ll}
\hline Characteristic & $\mathbf{n}(\%) \mathbf{n}=\mathbf{9 6}$ \\
\hline Feeding & \\
Oral feeding & $96(100)$ \\
Food consistency & \\
Whole & $60(62,5)$ \\
Chopped & $32(33,3)$ \\
Pureed & $4(4,2)$ \\
Number of meals a day & \\
2 to 4 meals & $35(36,4)$ \\
5 to 6 meals & $52(54,2)$ \\
More than 6 meals & $9(9,4)$ \\
Alcohol intake & $16(16,7)$ \\
Intake of nutritional supplements & $12(12,5)$ \\
Intake of multivitamins (vitamins and minerals) & $24(25)$ \\
Need of help to serve food in meals & $43(44,8)$ \\
Need of help for feeding (taking food to the mouth) & $4(4,2)$ \\
Feeding when the meal is not offered by the caregiver & \\
Patient eats normally & $36(37,5)$ \\
Patient eats less than usual & $30(31,3)$ \\
Patient does not eat & $30(31,3)$ \\
Recent reduction in appetite & $30(31,3)$ \\
Accept food that did not use to eat before the disease & $11(11,5)$ \\
\hline & \\
Do not accept food that used to eat before the disease & $17,7)$ \\
\hline
\end{tabular}

mild AD ( $\mathrm{n}=52,54.2 \%)$ and were at risk of malnutrition according to MNA $(\mathrm{n}=53,55.2 \%)$. According to the criteria of BMI, $53.1 \%$ of them had normal nutritional status $(n=51)$ and $27.1 \%$ were underweight $(n=26)$. Biochemical evaluation highlights a large number of individuals with reduced lymphocyte values $(n=52$, $55.3 \%$ ). Table 1 provides further information on the characteristics of the patients.

Regarding diet (table 2), all patients were oral fed and $62.5 \%(n=60)$ received normal consistency food. Most of them were independent for feeding (taking food to the mouth) $(n=92,95.8 \%)$, but $44.8 \%$ of them $(n=43)$ needed help to serve food during meals. When caregivers were asked if the patients had the initiative to self-feed when the meal was not offered by the caregiver, for example when they were alone, 31.3\% $(\mathrm{n}=30)$ answered that in this case the patients did not eat, and other 31.3\% ( $n=30)$ that they ate less than usual.

Table 3 presents data on the average daily food intake of the study population, demonstrating the dietary inadequacy of most patients.

When asked if the caregiver had doubts about the patient's diet, 39.6\% $(\mathrm{n}=38)$ answered affirmatively.

The feeding profile of the studied population was analyzed considering the different stages of dementia (table 4). Statistically significant difference was found between the mean values of energy intake in mild and moderate stages, with significantly lower values in the mild stage $(p=0.038)$. Also, there was statistically significant difference in the intake of nutritional supplements between mild and moderate stage $(p=0,002)$.

\section{Discussion}

The poor nutritional status of the studied population was evident with the results from MNA: $55.2 \%$ of the elderly were at risk of malnutrition and 5.2\% malnourished. However, when BMI is used, most of them have the diagnosis of normal weight $(53.1 \%)$ and $27.1 \%$ underweight. MNA probably reflects better the nutritional status of the elderly when compared to BMI because it considers more anthropometric measures, including those for muscle mass, as well as patient's medical history and diet.

The immunodeficiency of the study population should call attention, as $55.3 \%$ of the sample presented reduced lymphocytes values. According to Guigoz (22), immune function is impaired in the elderly with MNA score indicative of malnutrition.

This study highlights the difficulties related to feeding experienced by patients with $\mathrm{AD}$ and caregivers, which include the composition of the daily menu and the management of difficulties during meals. These difficulties might be related to the poor nutritional status found.

The change in the dietary patterns of older people with dementia, or even with mild cognitive impairment, was described in the study of Orsitto (8), in which these individuals had significantly lower scores on items of MNA about patient's diet, when compared to the ones without cognitive impairment $(p<0.001)$. In a prospective study about the clinical course of advanced dementia, Mitchell et al. (4) found that $86 \%$ of the evaluated elderly patients had eating problems during the study period, including weight loss, trouble with chewing or swallowing, refusal to eat or drink, suspected dehydration and persistently reduced oral intake. In advanced stage of dementia, these changes were associated with a 6-month mortality rate of $38.6 \%$ (4).

All subjects of the study were exclusively oral fed and $95.8 \%$ of them could self-feed, which reinforces the information that eating is typically the last basic activity of daily living (BADL) to become impaired in AD (23). Anyway, most patients need the caregiver to organize, offer the meal and serve the food to provide their food intake, which means they are semi-dependent for feeding.

Over $30 \%$ of primary caregivers mentioned patient's recent reduced appetite, and the frequency of this complaint seems to increase with worsening nutritional status. Previous studies have also reported high 
Table 3

Food intake of patients with Alzheimer disease

\begin{tabular}{|c|c|c|}
\hline Item & $\mathrm{n}(\%) \mathrm{n}=96$ & Mean \pm DP \\
\hline Energy (kcal/kg/day) & & $30,1 \pm 11,66$ \\
\hline Insufficient intake $(<90 \%)$ & $40(41,7)$ & \\
\hline Adequate intake ( $\geq 90$ and $\leq 110 \%$ ) & $26(27,1)$ & \\
\hline Excessive intake $(>110 \%)$ & $30(31,2)$ & \\
\hline Protein (g/kg/day) & & $1,1 \pm 0,46$ \\
\hline Insufficient intake $(<90 \%)$ & $45(46,9)$ & \\
\hline Adequate intake ( $\geq 90$ and $\leq 110 \%$ ) & $17(17,7)$ & \\
\hline Excessive intake $(>110 \%)$ & $34(35,4)$ & \\
\hline Liquids (ml/kg/day) & & $23,8 \pm 11,63$ \\
\hline Insufficient intake $(<90 \%)$ & $55(57,3)$ & \\
\hline Adequate intake ( $\geq 90$ and $\leq 110 \%$ ) & $15(15,6)$ & \\
\hline Excessive intake (> 110\%) & $26(27,1)$ & \\
\hline Vitamin A ( $\mu$ / day) & & $697,4 \pm 852,34$ \\
\hline Adequate intake & $25(26,0)$ & \\
\hline Insufficient intake & $71(74,0)$ & \\
\hline Vitamin C (mg/day) & & $94,2 \pm 102,37$ \\
\hline Adequate intake & $39(40,6)$ & \\
\hline Insufficient intake & $57(59,4)$ & \\
\hline Calcium (mg/day) & & $576,1 \pm 330,82$ \\
\hline Adequate intake & $3(3,1)$ & \\
\hline Insufficient intake & $93(96,9)$ & \\
\hline Iron (mg/day) & & $9,8 \pm 3,99$ \\
\hline Adequate intake & $62(64,6)$ & \\
\hline Insufficient intake & $34(35,4)$ & \\
\hline
\end{tabular}

prevalence of appetite disorders in this population (24). Most patients had up to four meals a day, when the recommendation is at least five meals a day.

The mean energy and protein intake of elderly patients, with values normalized to body weight, were $30.1 \mathrm{kcal} / \mathrm{kg} /$ day \pm 11.66 and $1.1 \mathrm{~g}$ protein $/ \mathrm{kg} /$ day \pm 0.46 respectively; values which give rise to the false interpretation that the diet is adequate, despite the high standard deviation in the average energy intake. Jesus et al. (7) found average intake of $27.1 \pm 8.7 \mathrm{kcal} / \mathrm{kg} /$ day and $1.1 \pm 0.4 \mathrm{~g}$ protein $/ \mathrm{kg} /$ day; Machado et al. (12) found 26.4 and $26.3 \mathrm{kcal} / \mathrm{kg} /$ day and 0.9 and 1.2 $\mathrm{g}$ protein $/ \mathrm{kg} /$ day in patients with mild and moderate stage of dementia respectively, values which are also apparently normal. In the present study the results were stratified according to the adequacy of nutrients intake for each patient, comparing consumption with the individualized nutritional recommendations, and thus, the high prevalence of dietary inadequacy of the studied population was evident. It is noteworthy that $41.7 \%$ of the patients consumed low calorie diets and $46.9 \%$ had low protein diets, beyond insufficient intake of vitamins
A and C, calcium and iron. These results support the hypothesis that low energy intake may contribute to unintentional weight loss in individuals with $\mathrm{AD}$ (5). According to Castaneda et al. (25), insufficient protein intake may result in loss of lean tissue, immune response and muscle function.

The poor diets may be related to patient's low education, since $71.9 \%$ of them attended only primary school, and to low-income, as $67.7 \%$ of families earned up to 2 Brazilian minimum wages per member. The brain disorder can also impair the regulation of food intake by the central nervous system $(2,6)$. Spaccavento et al. (2) hypothesized that changes in dietary habits and the onset of functional, cognitive and neuropsychiatric disorders in patients with $\mathrm{AD}$ reflect the involvement of a common neuroanatomical network. This can be due to the involvement of the prefrontal area with cortical and subcortical circuits, in programmed movement, behavioral control and in eating behavior regulation (2).

Only $12.5 \%$ of the patients received nutritional supplements regularly and $25 \%$ were taking multivitamin, perhaps due to the low purchasing power of the families or because they did not know these products. Despite the high prevalence of nutritional risk, the study population is not routinely assessed by dietitians and, thus, it is likely that dietary errors are not identified and treated promptly.

The patients in the mild stage of AD had significantly lower mean energy intake when compared to the ones in the moderate stage. Since patients in the mild stage usually have good level of independence for BADL, it is possible that they are not adequately monitored by caregivers with regard to food intake, despite the presence of some subtle negative changes in diet due to cognitive and behavioral impairment, which may influence the amount of ingested nutrients. In the study of Lin, Watson and $\mathrm{Wu}(26)$, patients with moderate feeding difficulties, but who could still self-feed, were ignored by the staff of the long-term care institutions where the study was conducted, whereas those with severe dependency who required feeding by nursing staff had better food intake. In both cases, patients who received more family visits at mealtimes, when family was encouraged to assist in the feeding of their relative, had better food intake (26).

The higher percentage of patients with adequate intake of vitamin A, vitamin C and calcium in severe stage of dementia may be due to the fact that their diets are more often chosen by caregivers, who probably select food of better nutritional quality.

After conducting a literature review about interventions that can be undertaken to establish and maintain adequate nutritional intake in older people with dementia, Cole (27) concluded that there is not a standardized intervention. The findings suggest that providing adequate training for staff and allowing more time to assist patients feeding have positive effects. Other 
Table 4

The feeding of patients, according to the stage of Alzheimer's disease

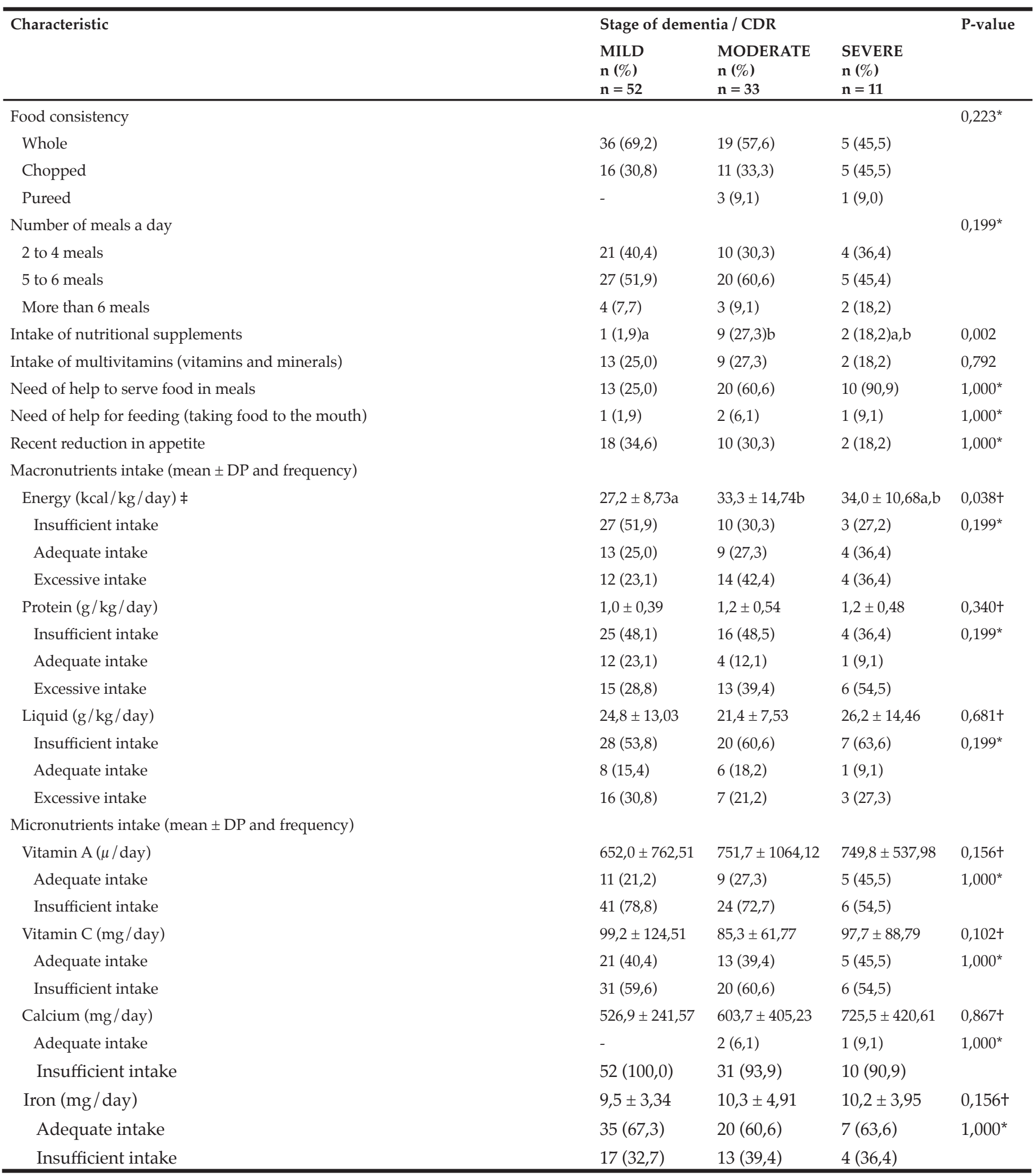

$\mathrm{CDR}=$ Clinical Dementia Rating; ${ }^{*}$ Chi-square test was used to assess differences in frequencies among the three groups of variables, considering significance level $\mathrm{p}<$ 0,05 ; † Kruskal-Wallis test was used to compare the mean values among the three groups, considering significance level $p<0,05$; $\neq$ Since $p$ value was significant $(p<0.05$ ), the Multiple Comparisons Test (considering significance level $\mathrm{p}<0,05$ ) was used to check for pairs of groups in which differences were found (mild vs moderate, mild vs severe, moderate vs. severe), represented by superscript letters. When the letters are different, there is a statistically significant difference between the pairs; when the letters are the same, no significant difference was found between the pairs. 
interventions mentioned were: engaging the advice of a dietitian, introduction of nutritional supplements, improvements in the mealtime environment and providing assistance with feeding before dietary intake declines dramatically (27).

The inadequate diet of the subjects is an important finding of this study and should call attention of health services for intervention. Diet influences the nutritional and clinical course of patients and thus, nutritional intervention should be early, appropriate and carried out by qualified dietitians. Some studies have been published suggesting that nutritional education programs intended for caregivers of $\mathrm{AD}$ patients could have a positive effect on patients and may improve weight, cognitive function (28), nutritional and immune status (29) and reduce the risk of malnutrition (30) in older individuals with dementia.

As a conclusion, caregivers should be informed about the need of specialized nutritional counseling and feeding assistance for the demented person since the early stage of the disease, when negative subtle changes may occur in dietary intake due to cognitive and behavioral impairment. These interventions may prevent the worsening of nutritional status and prognosis.

This study had some methodological limitations. The sample of patients with severe dementia was small, because the survey was conducted on an outpatient basis, which makes their access difficult. Also, the most fragile patients were excluded because of their impossibility to stand to weight. Studies should be directed to populations with these conditions.

Disclosures: Danielle Rodrigues Lecheta reports no conflicts of interest. Maria Eliana Madalozzo Schieferdecker reports no conflicts of interest. Ana Paula de Mello reports no conflicts of interest. Ivete Berkenbrock reports no conflicts of interest. João Cardoso Neto reports no conflicts of interest. Eliane Mara Cesário Pereira Maluf reports no conflicts of interest.

Funding: This study had no sponsors.

Acknowledgments: The authors gratefully acknowledge the participation of the patients and their caregivers, and the contribution of the staff of Health Center of Elderly Care Ouvidor Pardinho.

\section{References}

1. WHO, World Health Organization. Dementia: a public health priority. 2012. World Health Organization, Geneva.

2. Spaccavento S, Prete MD, Craca A, Fiore P. Influence of nutritional status on cognitive, functional and neuropsychiatric deficits in Alzheimer's disease. Arch Gerontol Geriatr 2009; 48:356-360.

3. Gillette-Guyonnet S, Nourhashémi F, Andrieu S, et al. Weight loss in Alzheimer disease. Am J Clin Nutr 2000; 71:637S-642S.

4. Mitchell SL, Teno JM, Kiely DK, et al. The clinical course of advanced dementia. N Engl J Med 2009; 361:1529-1538.

5. Poehlman ET, Dvorak RV. Energy expenditure, energy intake, and weight loss in Alzheimer disease. Am J Clin Nutr 2000; 71:650S-655S.
6. Burns JM, Johnson DK, Watts A, Swerdlow RH, Brooks WM. Reduced lean mass in early Alzheimer disease and its association with brain atrophy. Arch Neurol 2010; 67:428-433.

7. Jesus P, Desport JC, Massoulard A, et al. Nutritional assessment and followup of residents with and without dementia in nursing homes in the Limousin region of France: a health network initiative. J Nutr Health Aging 2012; 16:504-508.

8. Orsitto G. Different components of nutritional status in older inpatients with cognitive impairment. J Nutr Health Aging 2012; 16:468-471.

9. Zekry D, Herrmann FR, Grandjean R, et al. Demented versus non-demented very old inpatients: the same comorbidities but poorer functional and nutritional status. Age ageing 2008; 37:83-89.

10. Roque M, Salva A, Vellas B. Malnutrition in community-dwelling adults with dementia (NutriAlz trial). J Nutr Health Aging 2013; 17:295-299.

11. Isaia G, Mondino S, Germinara C, et al. Malnutrition in an elderly demented population living at home. Arch Gerontol Geriatr 2011; 53:249-251.

12. Machado J, Caram CLB, Frank AA, Soares EA, Laks J. Estado nutricional na doença de Alzheimer. Rev Assoc Med Bras 2009; 55:188-191.

13. Wang PN, Yang CL, Lin KN, Chen WT, Chwang LC, Liu HC. Weight loss, nutritional status and physical activity in patients with Alzheimer disease: a controlled study. J Neurol 2004; 251:314-320.

14. McKhann G, Drachman D, Folstein M, Katzman R, Price D, Stadian EM. Clinical diagnosis of Alzheimer's disease: report of the NINCDS-ADRDA Work Group under the auspices of Department of Health and Human Services Task Force on Alzheimer's Disease. Neurology 1984; 34:939-944.

15. Hughes CP, Berg L, Danziger WL, Coben LA, Martin RL. A new clinical scale for the staging of dementia. Br J Psychiatry 1982; 140:566-572.

16. Morris J. The Clinical Dementia Rating (CDR): current version and scoring rules. Neurology 1993; 43:2412-2414.

17. Guigoz Y, Vellas B, Garry PJ. Mini nutritional assessment: a practical assessment tool for grading the nutritional state of elderly patients. Fact and Research in Gerontology 1994; 2:15-59.

18. Bottoni A, Oliveira GPC, Ferrini MT, Waitzberg DL. Avaliação nutricional: exames laboratoriais. In: Waitzberg DL. Nutrição oral, enteral e parenteral na prática clínica, 3rd edn. 2006. Atheneu, São Paulo, pp 279-294.

19. Institute of Medicine. Food and Nutrition Board. Dietary Reference Intakes for energy, carbohydrates, fiber, fat, protein and amino acids (macronutrients). 2005. National Academy Press, Washington.

20. ASPEN, American Society for Parenteral and Enteral Nutrition. The ASPEN nutrition support practice manual. 1998. ASPEN, Silver Spring.

21. Brasil, Banco Central do Brasil. Taxas de câmbio do real. 2013. http: / / www. ipeadata.gov.br/ Acessed 13 December 2013.

22. Guigoz Y. The mini nutritional assessment $(\mathrm{MNA} \otimes)$ : review of the literature - what does it tell us? J Nutr Health Aging 2006; 10:466-487.

23. Cervo FA, Bryan L, Farber S. To PEG or not to PEG: a review of evidence for placing feeding tubes in advanced dementia and the decision-making process. Geriatrics 2006; 61:30-35.

24. Salva A, Andrieu S, Fernandez E, et al. Health and nutritional promotion program for patients with dementia (NutriAlz study): design and baseline data. J Nutr Health Aging 2009; 13:529-537.

25. Castaneda C, Charnley JM, Evans WJ, Crim MC. Elderly women accommodate to a low-protein diet with losses of body cell mass, muscle function, and immune response. Am J Clin Nutr 1995; 62:30-39.

26. Lin L, Watson $\mathrm{R}, \mathrm{Wu} \mathrm{S}$. What is associated with low food intake in older people with dementia? J Clin Nurs 2010; 19:53-59.

27. Cole D. Optimising nutrition for older people with dementia. Nurs Stand 2012; 26: 41-48

28. Riviere S, Gillette-Guyonnet S, Voisin T, et al. A nutritional education program could prevent weight loss and slow cognitive decline in Alzheimer's disease. J Nutr Health Aging 2001; 5:295-299.

29. Pivi GAK, Silva RV, Juliano Y, et al. A prospective study of nutrition education and oral nutritional supplementation in patients with Alzheimer's disease. Nutrition Journal 2011; 10:1-6.

30. Salva A, Andrieu S, Fernandez E, et al. Health and nutrition promotion program for patients with dementia (NutriAlz study): cluster randomized trial. J Nutr Health Aging 2011; 15:822-830. 